\title{
DIAGONAL COMPRESSIVE CAPACITY OF REINFORCED CONCRETE BEAMS WITH WIDE STIRRUP SPACING
}

\author{
Patarapol TANTIPIDOK¹, Koji MATSUMOTO² and Junichiro NIWA ${ }^{3}$ \\ ${ }^{1}$ Non-member of JSCE, Ph.D. Candidate, Dept. of Civil Eng., Tokyo Institute of Technology \\ (2-12-1-M1-17 O-okayama, Meguro-ku, Tokyo 152-8552, Japan) \\ E-mail: tantipidok.p.aa@m.titech.ac.jp \\ ${ }^{2}$ Member of JSCE, Assistant Professor, Dept. of Civil Eng., Tokyo Institute of Technology (ditto) \\ E-mail: matsumoto.k.ar@m.titech.ac.jp \\ ${ }^{3}$ Fellow of JSCE, Professor, Dept. of Civil Eng., Tokyo Institute of Technology (ditto) \\ E-mail: jniwa@cv.titech.ac.jp
}

\begin{abstract}
To promote more widespread use of high-strength concrete (HSC) for the efficient design of reinforced concrete (RC) beams, an experimental investigation on the effect of wide stirrup spacing on the diagonal compressive capacity of HSC beams was performed. The predictive equation for the diagonal compressive capacity of RC beams proposed by the authors was modified to cover the application to RC beams with wide stirrup spacing. Four 590-mm deep I-beams with wide stirrup spacing were tested by three-point bending. The influence of stirrup spacing, stirrup diameter, and the number of stirrup legs was discussed. The results show that the diagonal compressive capac ity linearly decreased with wider stirrup spacing regardless of its diameters when stirrup spacing was narrower than $140 \mathrm{~mm}$; however, the effect of spacing became negligible when stirrup spacing was wider than $140 \mathrm{~mm}$. Even when wide stirrup spacing was used, the diagonal compressive stress did not concentrate on the local area of the specimens and a sufficient confinement effect was achieved by providing two-legged stirrups; the localization of compressive stress on the struts was likewise prevented. Finally, the predictive equation by the authors was modified on the basis of the experimental findings. The modified equation covers the application to RC beams with wide stirrup spacing while maintaining adequate simplicity and precise prediction of the diagonal compressive capacity of RC beams.
\end{abstract}

Key Words: diagonal compressive capacity, web crushing, high-strength concrete, predictive equation

\section{INTRODUCTION}

For the past decade, the increasing rate of global warming has led structural engineers to focus on verifying the ultimate limit resistance, as well as the durability and sustainability of concrete structures. The utilization of high-strength concrete (HSC) is one of the approaches used to reduce $\mathrm{CO}_{2}$ emission due to construction activities and to achieve sustainable communities. HSC results in lower material consumption (smaller cross section and number of spans) and longer service life of structures, while maintaining a remarkable structural performance. To fully utilize the advantages of high-strength properties, the combination of thin web (T- or I-shaped cross section) HSC beams and high-strength stirrups is introduced. However, when excessive stirrups are provided, this combination will lead to diagonal compression failure, that is, an uncommon type of shear failure caused by the crushing of web concrete prior to stirrup yielding.

Research on the mechanism of diagonal compression failure is usually avoided and is therefore insufficient. The JSCE $^{1)}$ standard specifications for diagonal compressive capacity provide inadequate accuracy, resulting in extravagant and inefficient designs of reinforced concrete (RC) beams. Furthermore, only a few studies have been performed on the diagonal compressive capacity of HSC beams, with the exception of a recent research by the authors ${ }^{2}$. Experiments on HSC I-beams were carried out to investigate the effect of various parameters on the diagonal compressive capacity. It was concluded that the major factors affecting the diagonal compressive capacity were $f_{c}^{\prime}$ and stirrup spacing (s). The effects of the shear span-to-effective depth ratio $(a / d)$, flange 
width-to-web width ratio $\left(b_{f} / b_{w}\right)$, and the effective depth $(d)$ were found to have less influence in their study range. Subsequently, an accurate and simple predictive equation was proposed on the basis of the experimental results. In the case of stirrup spacing, the proposed equation can be applied for the range of 45-160 mm. However, in real structures, for which the size of RC beams can be relatively large, stirrup spacing can exceed $160 \mathrm{~mm}$ and the equation may not be applicable.

This research aims to investigate the effect of stirrup spacing larger than $160 \mathrm{~mm}$ on the diagonal compressive capacity of RC beams. It also aims to extend the applicability of the predictive equation by the authors to RC beams with wide stirrup spacing, with a view to promoting the rational design and more widespread use of HSC. Four 590-mm deep I-beams were tested by three-point bending. The influence of stirrup spacing (s), stirrup diameter $\left(\phi_{d}\right)$, and the number of stirrup legs on the diagonal compressive capacity was discussed. Subsequently, the predictive equation by the authors was modified on the basis of experimental findings to extend the applicability to RC beams with wide stirrup spacing. Finally, the accuracy of both the existing equations and that of the modified equation were verified and compared.

\section{REVIEW OF THE EXISTING EQUA- TIONS FOR DIAGONAL COMPRES- SIVE CAPACITY}

\section{(1) The equation by the authors}

The authors investigated the effect of $f_{c}^{\prime}$, stirrup ratio $\left(r_{w}=100 A_{w} /\left(b_{w} s\right)(\%)\right), s, a / d, b_{f} / b_{w}$, and $d$ on the diagonal compressive capacity. Then, on the basis of the experimental results, they proposed a simple predictive equation as follows ${ }^{2}$ :

$$
V_{c a l}=\left(1.9-\frac{s}{190}\right) \sqrt{f^{\prime}{ }_{c}} b_{w} d
$$

where $f_{c}^{\prime}$ and $s$ are in $\mathrm{N} / \mathrm{mm}^{2}$ and $\mathrm{mm}$, respectively.

The equation considers the equilibrium condition of web concrete at the critical section. It also assumes the average distribution of diagonal compressive stress on the web and the member failure caused by the crushing of web concrete without the stirrups yielding. The equation was empirically derived by using the trends of the results, which showed that the diagonal compressive capacity linearly decreased with larger stirrup spacing regardless of its diameter. This is due to the insufficient confinement effects provided by the stirrups, which caused the localization of compressive stress on the struts. Thus, $s$, which ranged from 45 to $160 \mathrm{~mm}$, was prominent, rather than $r_{w}$, in evaluating the diagonal compressive capacity. The effect of spacing became more significant with higher concrete strength; hence, the effects of $f_{c}^{\prime}$ and $s$ were interrelated. On the other hand, the effects of $a / d$ from 3.0 to $4.5, b_{f} / b_{w}$ from 3.75 to 12.5 , and $d$ from $220 \mathrm{~mm}$ to $319 \mathrm{~mm}$ had almost no influence on the diagonal compressive capacity of the RC beams. The equation can be implemented on beams with $f_{c}^{\prime}: 19-165 \mathrm{~N} / \mathrm{mm}^{2}, r_{w}: 0.6-4 \%$, s: $45-160 \mathrm{~mm}$, $b_{f} / b_{w}: 3.75-12.5, a / d: 2.5-4.5$, and $d: 220-563 \mathrm{~mm}$.

\section{(2) The equation by Placas and Regan}

Placas and Regan proposed an empirical equation for evaluating the diagonal compressive capacity as follows ${ }^{3)}$ :

$$
V_{\text {Placas }}=\left(1.04+0.21 r_{w}\right) \sqrt{f^{\prime}{ }_{c}} b_{w} d
$$

The factors involving the diagonal compressive capacity in this equation are $f_{c}^{\prime}$ and the stirrup ratio $r_{w}$ (\%). Although no upper limit of $f_{c}^{\prime}$ is stated in this equation, the experimental evidence used to derive this equation is approximately $35 \mathrm{~N} / \mathrm{mm}^{2}$.

\section{(3) JSCE Standard Specifications}

In the JSCE standard specifications ${ }^{1)}$, only $f_{c}^{\prime}$ is considered as the influential parameter of diagonal compressive capacity. Because this formula was originally proposed for application to normal-strength concrete, the equation is only valid for concrete with $f_{c}^{\prime}$ not exceeding $50 \mathrm{~N} / \mathrm{mm}^{2}$.

$$
V_{J S C E}=1.25 \sqrt{f^{\prime}{ }_{c}} b_{w} d
$$

\section{EXPERIMENTAL PROGRAM}

\section{(1) Specimen details}

The experimental program prepared four RC beams with I-shaped cross section. Three-point bending tests were conducted using a $3000 \mathrm{kN}$ capacity loading apparatus. Assuming $d$ had no effect based on the previous result ${ }^{2}$, the size of the specimens in this research was greatly enlarged compared to the previous one to provide a wider $s$. The summary of the experimental parameters and details of specimens are provided in Table 1 and Fig. 1, respectively. The main parameters were stirrup spacing ( $s=230,300$, and $370 \mathrm{~mm})$, stirrup diameter $\left(\phi_{d}\right.$ $=13.1$ and $15.9 \mathrm{~mm}, A_{w}=125 \mathrm{~mm}^{2}$ and $198.6 \mathrm{~mm}^{2}$ ), and number of stirrup legs (one and two). The constant variables were the following: web width $\left(b_{w}\right)$ of $80 \mathrm{~mm}$, effective depth $(d)$ of $500 \mathrm{~mm}$, shear span $(a)$ of $1500 \mathrm{~mm}, a / d$ ratio of 3.0, longitudinal reinforcement ratio of $8.9 \%$ and total length of $3600 \mathrm{~mm}$. Tensile reinforcements had two layers in which D22s $\left(A_{s}=380.1 \mathrm{~mm}^{2}\right)$ were used for the top layer (Top), 
while the bottom layer (Bottom) used D25s $\left(A_{s}=\right.$ $490.9 \mathrm{~mm}^{2}$ ). Compressive reinforcements used D32s $\left(A_{s}^{\prime}=804.2 \mathrm{~mm}^{2}\right)$. Stirrups were anchored around a tensile bar using semi-circular hook type with 32.5 mm hook radius.

All specimens were designed to be symmetric and be able to resist flexure failure and diagonal tension failure by using high-strength reinforcing bars ( $f_{y}$ and $f_{w y}>916 \mathrm{~N} / \mathrm{mm}^{2}$ ) as both tensile and shear reinforcements. In addition, the combination of thin web cross section with dense stirrups would have caused the specimens to exhibit a diagonal compression failure. To avoid local failure, the web width outside support was increased in relation to the bottom flange. Anchor plates and nuts were used to ensure sufficient anchorage of the tensile bars and prevent anchorage failure.

\section{(2) Instrumentation and test procedures}

For all specimens, the applied load, midspan deflections and strains of concrete, tensile bars, and stirrups were measured. Concrete strain gauges were attached to the top fiber of the midspan. Strain gauges were attached to the midspan to measure the strain of longitudinal bars, and at a distance of $d / 2$ from the top fiber for all stirrups in the shear spans. The angle of the principal strain of web concrete was measured using tri-axis strain gauges. The locations of these strain gauges are illustrated in Fig. 2. Both surfaces of all specimens were painted white for easy drawing and observation of cracks during the experiments. Pictures were taken using two digital single-lens reflex cameras for both shear spans.

From the pictures taken at the peak load, the crack spacing in horizontal direction $\left(s_{c i}\right)$ and the crack angle $\left(\beta_{i}\right)$ were measured at the middle height of the web. An example of $s_{c i}$ and $\beta_{i}$ measurement of a crack is presented in Fig. 3. The average of $s_{c i}$ of cracks in the shear span $\left(s_{c, a v g}\right)$ and the average of $\beta_{i}$ of cracks in the B-region $\left(\beta_{\text {avg }}\right)$ will be used in the later discussion since it was observed that the crushing area, which corresponds to the failure region, was mostly found in the B-region (the portion outside the distance approximately $d$ away from the loading point and supports).

\section{EXPERIMENTAL RESULTS}

\section{(1) General behavior and failure mode}

The load-deflection relationships are illustrated in Fig. 4. First, specimens behaved in an elastic manner until the first flexural crack occurred at the bottom flange near the midspan, which is reflected in the

Table 1 List of the experimental cases.

\begin{tabular}{|c|c|c|c|c|c|c|c|c|c|c|c|c|}
\hline \multirow[b]{2}{*}{ Specimen } & \multirow{2}{*}{$\begin{array}{c}f_{c}^{\prime} c \\
{\left[\mathrm{~N} / \mathrm{mm}^{2}\right]}\end{array}$} & \multirow{2}{*}{$\begin{array}{c}b_{w} \\
{[\mathrm{~mm}]}\end{array}$} & \multirow{2}{*}{$\underset{[\mathrm{mm}]}{d}$} & \multirow{2}{*}{$\begin{array}{c}a \\
{[\mathrm{~mm}]}\end{array}$} & \multirow[b]{2}{*}{$a / d$} & \multirow{2}{*}{$\begin{array}{l}p_{w}{ }^{* 1} \\
{[\%]}\end{array}$} & \multirow{2}{*}{$\begin{array}{c}D^{* 2} \\
{[\mathrm{~mm}]}\end{array}$} & \multicolumn{5}{|c|}{ Stirrup properties } \\
\hline & & & & & & & & $\begin{array}{c}\phi_{d}{ }^{* 3} \\
{[\mathrm{~mm}]}\end{array}$ & $\begin{array}{c}f_{w y}^{{ }^{*} 4} \\
{\left[\mathrm{~N} / \mathrm{mm}^{2}\right]}\end{array}$ & $\begin{array}{c}\text { No. of } \\
\text { legs }\end{array}$ & $\begin{array}{l}r_{w}{ }^{* 5} \\
{[\%]}\end{array}$ & $\begin{array}{c}s^{* 6} \\
{[\mathrm{~mm}]}\end{array}$ \\
\hline s300-II & \multirow{4}{*}{100} & \multirow{4}{*}{80} & \multirow{4}{*}{500} & \multirow{4}{*}{1500} & \multirow{4}{*}{3.0} & \multirow{4}{*}{8.9} & \multirow{2}{*}{$\begin{array}{l}22.2 \\
\text { (top) }\end{array}$} & \multirow{2}{*}{13.1} & \multirow{3}{*}{1368} & \multirow{3}{*}{ Two } & 1.06 & 300 \\
\hline s370-II(13) & & & & & & & & & & & 0.88 & \multirow{2}{*}{370} \\
\hline s370-II(16) & & & & & & & $\begin{array}{l}25.4 \\
\text { (bot- }\end{array}$ & 150 & & & 1.34 & \\
\hline s230-I & & & & & & & tom) & & 926 & One & 1.08 & 230 \\
\hline
\end{tabular}

${ }^{* 1}$ longitudinal reinforcement ratio $\left(=100 A_{s} /\left(b_{w} d\right)\right),{ }^{* 2}$ nominal diameter of tensile bars, ${ }^{* 3}$ nominal diameter of stirrups,

${ }^{*}$ yield strength of stirrups, ${ }^{* 5}$ stirrup ratio $\left(=100 A_{w} /\left(b_{w} s\right)\right),{ }^{* 6}$ spacing of stirrups

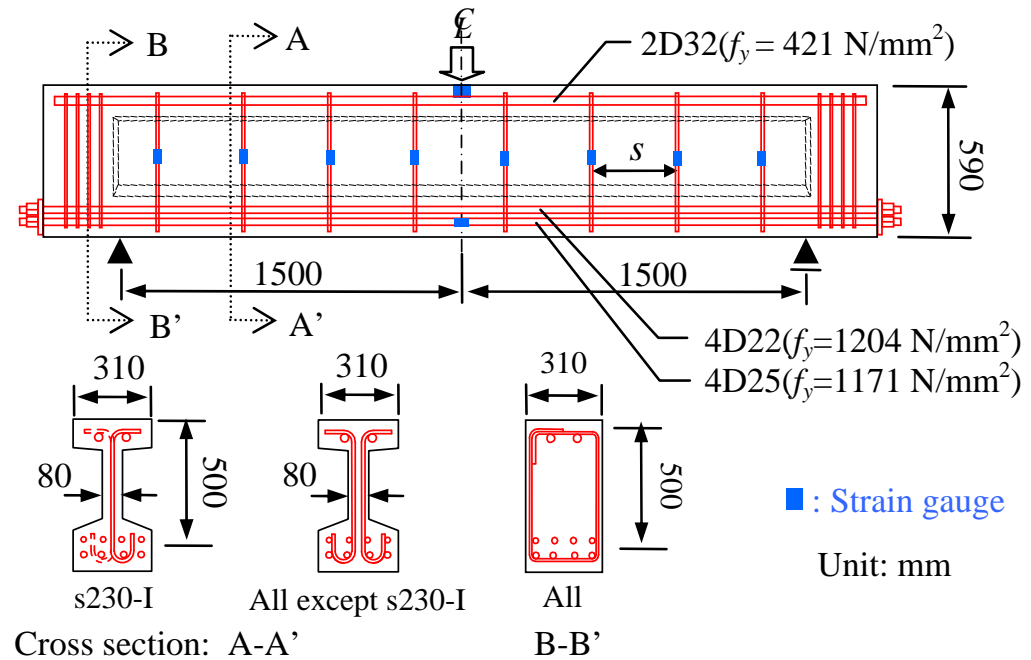

Fig. 1 Dimensions of specimens and layout of steel bars.

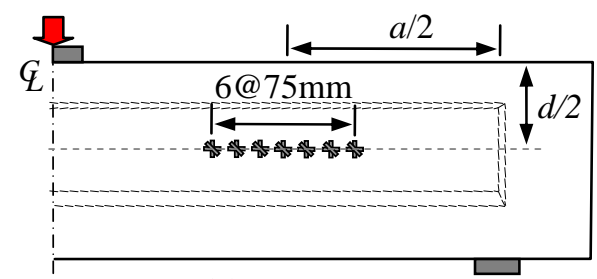

(a) For s300-II

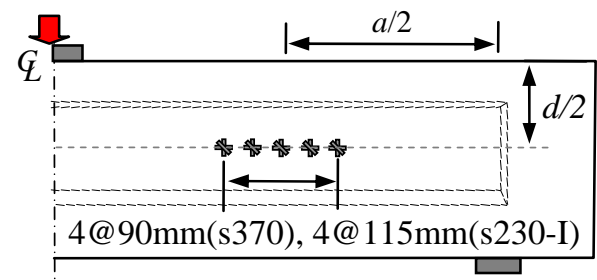

(b) For all except s300-II

Fig. 2 Location of tri-axis strain gauges. 


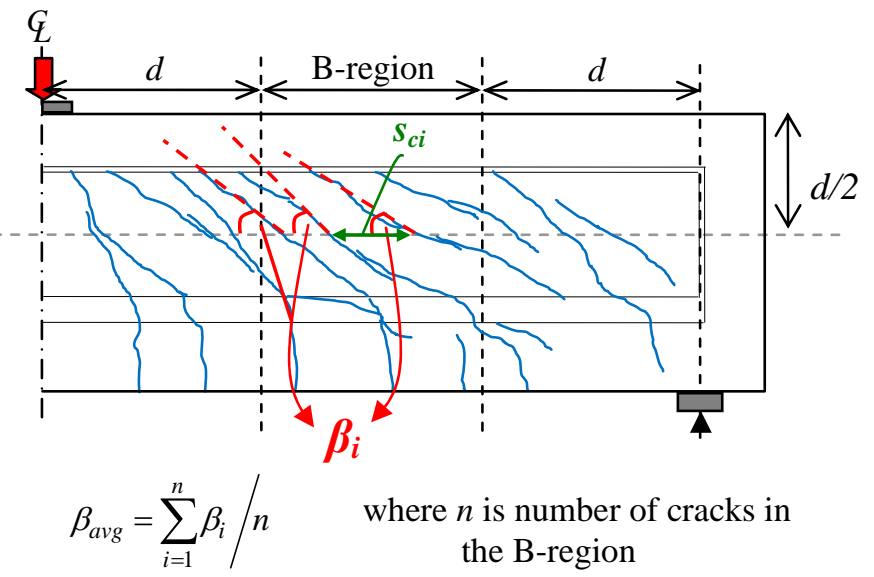

Fig. 3 Example of crack spacing and angle measurement.

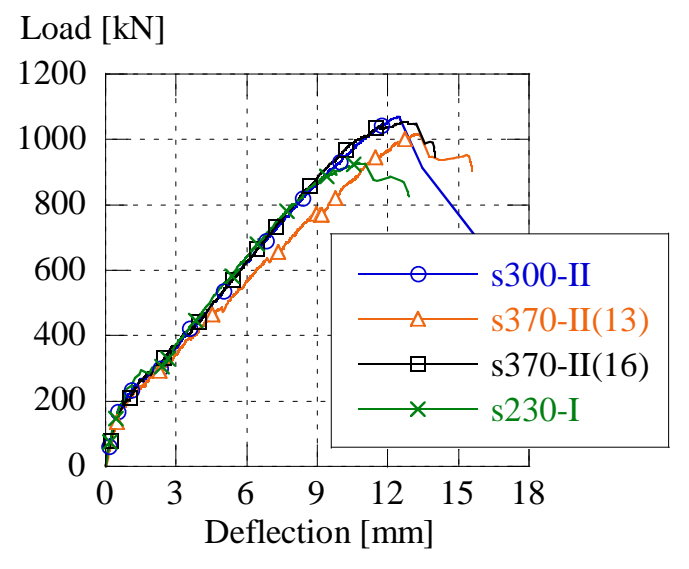

Fig. 4 Load-deflection relationship.

Table 2 Experimental results.

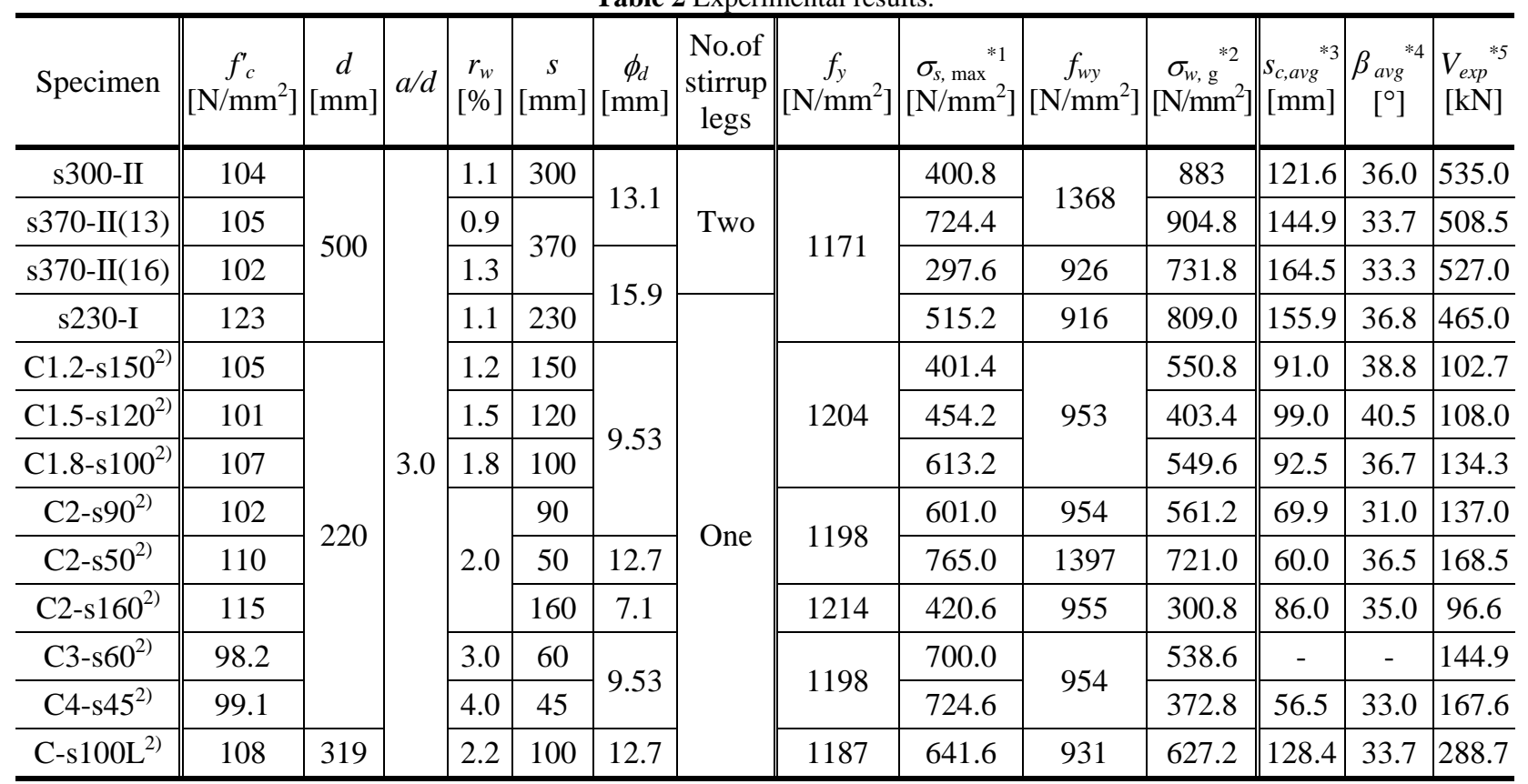

${ }^{* 1}$ maximum stress in tensile bars, ${ }^{* 2}$ maximum stress in stirrups, ${ }^{* 3}$ average crack spacing in horizontal direction at peak load, ${ }^{* 4}$ average crack angle in the B-region at peak load, ${ }^{* 5}$ diagonal compressive capacity

graph as the rate of inclination decreases. After the first flexural crack, the load-deflection curve remained to advance linearly with the continuous initiation of diagonal cracks at the web concrete. In the pre-peak region, the deflection increased with a relatively small increase in the applied load as the web concrete began to crush. Afterwards, the applied load reached the peak. After the peak load, the applied load rapidly decreased. The experimental results are summarized in Table 2. The data on the stresses of longitudinal bars and stirrups revealed no yielding at the peak load. It implies that the failure mode was neither a flexure failure nor a diagonal tension failure. The web concrete crushed at the peak load and splitting cracks along the member axis near the tensile bars did not initiate at that time; hence, the cause of failure was not the anchorage failure of both tensile bars and stirrups. Considering these observations, it can be concluded that all specimen failures were diagonal compression failures, in which the web concrete crushed before the yielding of stirrup exhibited a brittle mode. Crack patterns just before the peak load are demonstrated in Fig. 5. The thicker lines, the shaded areas, and red lines represent the wider crack widths, the crushing areas, and the location of stirrups, respectively.

\section{(2) Effect of wide stirrup spacing}

The authors ${ }^{2)}$ adopted a method to eliminate the variation of $f^{\prime}$, by normalizing the obtained shear strengths $\left(v_{\text {exp }}=V_{\text {exp }} /\left(b_{w} d\right)\right)$ by $f_{c}^{\prime 1 / 2}$, which is used in the design equation of $\mathrm{JSCE}^{1)}$ and the predictive equation by Placas and Regan ${ }^{3)}$. This method is also applied in this study. The relationships between $s$ and $v_{\text {exp }} / f_{c}^{\prime 1 / 2}$, including the specimens in the authors' previous experiment ${ }^{2}$, Rangan ${ }^{4)}$ and Leonhardt and Walther ${ }^{5)}$ are demonstrated in Fig. 6. The specimens 


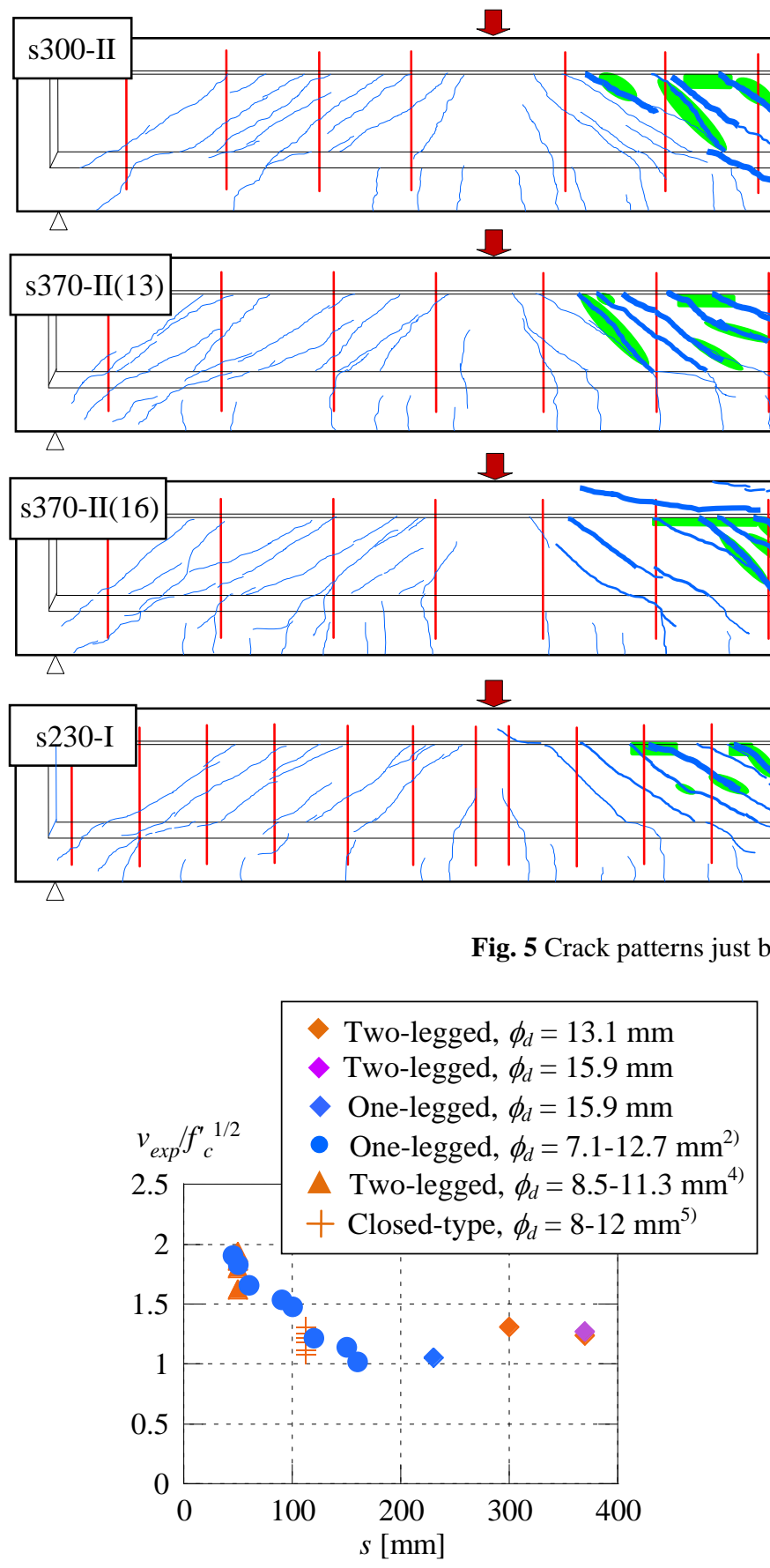

Fig. 6 Effect of $s$. in the previous research ${ }^{2)}$ had $s$ in the range of 45-160 mm with one-legged stirrup and $d$ of 220 $\mathrm{mm}$, while beams in this study had $s=230 \mathrm{~mm}$ (one-legged stirrup), 300 and $370 \mathrm{~mm}$ (two-legged strirrup), and $d=500 \mathrm{~mm}$. The details of specimens in the study of Rangan ${ }^{4)}$ and Leonhardt and Walther ${ }^{5)}$ are provided in Table 3. Figure 6 shows that the diagonal compressive capacity has a linear relationship with $s$ regardless of its diameters and configuration in the range of $45 \mathrm{~mm} \leq s \leq 160 \mathrm{~mm}$ as reported by the authors ${ }^{2}$. However, according to the results of this study, the change in $v_{\text {exp }} / f_{c}^{\prime 1 / 2}$ becomes negligible when $s$ is wider than approximately $140-160 \mathrm{~mm}$. Specimens with the same $s$ but dif-

\section{Legends:}

Thicker line $=$ wider crack width Shaded area $=$ crushing area Red line $=$ stirrups 
Table 3 List of details of the specimens and results from the other authors.

\begin{tabular}{|c|c|c|c|c|c|c|c|c|c|c|c|}
\hline Specimen & {$\left[\begin{array}{c}f_{c}^{\prime} \\
{\left[\mathrm{N} / \mathrm{mm}^{2}\right]}\end{array}\right.$} & $\begin{array}{c}b_{w} \\
{[\mathrm{~mm}]}\end{array}$ & $\begin{array}{c}d \\
{[\mathrm{~mm}]}\end{array}$ & $a / d$ & $\begin{array}{c}p_{w} \\
{[\%]}\end{array}$ & $\begin{array}{c}r_{w} \\
{[\%]}\end{array}$ & $\begin{array}{c}S \\
{[\mathrm{~mm}]}\end{array}$ & $\begin{array}{c}\phi_{d} \\
{[\mathrm{~mm}]}\end{array}$ & $\begin{array}{l}\text { Stirrup Con- } \\
\text { figuration }\end{array}$ & $\begin{array}{c}f_{w y} \\
{\left[\mathrm{~N} / \mathrm{mm}^{2}\right]}\end{array}$ & $\begin{array}{l}V_{\text {exp }} \\
{[\mathrm{kN}]}\end{array}$ \\
\hline $\mathrm{I} 1^{4)}$ & 36.5 & \multirow{2}{*}{74} & \multirow{4}{*}{563} & \multirow{4}{*}{2.5} & 0 & 2.7 & \multirow{4}{*}{50} & 11.3 & \multirow{4}{*}{ Two-legged } & \multirow{4}{*}{485} & 453 \\
\hline$I 2^{4)}$ & 30.2 & & & & 8.4 & 1.5 & & 8.5 & & & 371 \\
\hline I $3^{4)}$ & 31.2 & 63 & & & 9.8 & 3.2 & & 11.3 & & & 369 \\
\hline $\mathrm{I} 4^{4)}$ & 35.7 & 64 & & & 9.7 & 1.8 & & 8.5 & & & 416 \\
\hline TA1 $1^{5)}$ & 20.6 & \multirow{6}{*}{150} & \multirow{6}{*}{375} & \multirow{6}{*}{3.3} & \multirow{6}{*}{4.7} & 1.3 & \multirow{6}{*}{113} & 12 & \multirow{6}{*}{ Closed-type } & 426 & 335 \\
\hline $\mathrm{TA2}^{5)}$ & 20.6 & & & & & 0.86 & & 10 & & 425 & 301 \\
\hline $\mathrm{TA3}^{5)}$ & 19.1 & & & & & 0.59 & & 8 & & 417 & 272 \\
\hline TA13 $^{5)}$ & 23.7 & & & & & 1.29 & & 12 & & 426 & 343 \\
\hline $\mathrm{TA} 4^{5)}$ & 23.7 & & & & & 0.86 & & 10 & & 425 & 333 \\
\hline TA15) & 23.2 & & & & & 0.59 & & 8 & & 417 & 292 \\
\hline
\end{tabular}

mechanisms caused by the confinement effect of the stirrups. One is the smaller diagonal crack width $(w)$ caused by providing closer shear reinforcements; therefore, the critical average stress in web concrete $\left(\sigma_{2 \max }\right)$ will be greater because $w$ affects the diagonal compressive capacity as likewise reported by Schäfer et al. ${ }^{6)}$ and Reineck ${ }^{7}$. The other is the localization of the compressive strut, which resulted from an insufficient confinement effect provided by the stirrups. The presence of confinement effect by the stirrups can prevent the excessive crack opening so that stress is distributed along the beam axis. In addition, it should be noted that the confinement effect provided by the stirrups in thin web beams is different from the one provided by tie reinforcements in columns, which increases the strength of core concrete inside the tie reinforcements. Such confinement effect rarely exists in thin web RC beams (large web height-to-web width ratio), in which diagonal compression failure generally occurs. The diagonal compression failure is not likely to occur in RC beams with adequately low ratio of web height to web width that could cause considerable confinement effect.

Figure 7 explains the model of compressive strut formation under different stirrup spacing. Figure 7(a) demonstrates that diagonal stress is generated uniformly along the beam axis with close-spacing stirrups. In contrast, as shown in Fig. 7(b), the diagonal stress is concentrated on a local portion of the beam with wide-spacing stirrups. This stress concentration causes the early crushing of web concrete and the reduction of diagonal compressive capacity. Moreover, there was indication that in the case of closer-spacing specimens, cracks were finely distributed and the crushing area at the web was more widespread than that of the wider-spacing specimens. Likewise, $s_{c, a v g}$ tended to decrease with closer stirrup spacing, indicating that the localization failure occurred when wider $s_{c, \text { avg }}$ were observed ${ }^{2}$. "In addi-
- The authors ${ }^{2)}$

- Zakaria et al. ${ }^{8}$

Normalized average crack spacing

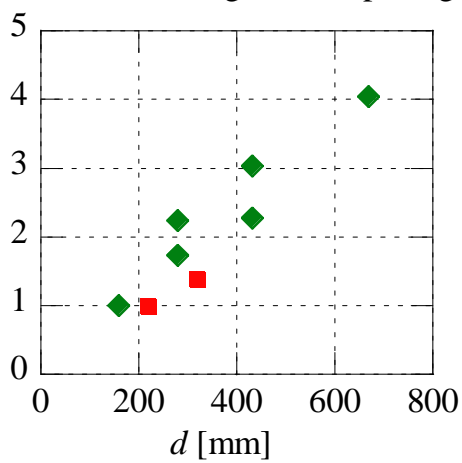

Fig. 8 Effect of $d$ on diagonal crack spacing.

tion, Zakaria et al. ${ }^{8)}$ reported that larger beams caused greater average crack spacing at the peak load. The specimens, which had the smallest effective depth in this and Zakaria's study, were selected as the reference beams. The relationship between the average crack spacing at the peak load normalized by the average crack spacing of the reference beam and the effective depth is illustrated in Fig. 8. It can be observed that the normalized crack spacing increases proportionally with the increase in effective depth.

However, in this research, even though $s$ was greatly increased, the diagonal compressive capacity did not decrease when using two-legged stirrups (s300-II, s370-II(13) and s370-II(16)) compared to s230-I. Cracks distributed finely and the crushing area at the web distributed widely as can be observed from Fig. 5. Considering the previous results in which $s_{c, a v g}$ should be proportional to the increase of $s$ and $d, s_{c, a v g}$ of specimens with two-legged stirrups were relatively narrow. In addition, $s_{c, \text { avg }}$ of specimens with the same $r_{w}$ (s230-I and s300-II) but different $s, \phi_{d}$ and number of legs were compared. Finer crack distribution and smaller $s_{c, a v g}$ were observed for 
s300-II, even if s230-I had a narrower $s$ and larger $\phi_{d}$. This is because one-legged stirrup was provided in s230-I. These pieces of evidence imply that the confinement effect of the stirrups was sufficient in the case of two-legged stirrups and the diagonal stress did not concentrate on a local area of the specimens even if wide stirrup spacing was used. It is because the use of two-legged stirrups of $\phi_{d}=13.1 \mathrm{~mm}$ in this study resulted in a higher effective area in which the confinement effect (due to the stirrup) can control excessive crack opening, while the use of one-legged stirrup in the previous experiment and s230-I (for which the effective area was comparatively smaller), induced the localization of compressive strut.

\section{(3) Angle of principal strain and diagonal cracks}

The results of the measured angle of principal strain at the peak load are exhibited in Fig. 9. The location of the measurement is shown in Fig. 2. To avoid excessive measured tensile strain, some gauges, which were propagated through diagonal cracks, were defined as broken and were excluded from the calculation. The angle of principal strain varies from 21.3 to 36.9 degrees. The average angle of the principal strain of s300-II, s370-II(13), s370-II(16), and s230-I are 29.6, 31.2, 28.2, and 30.3 degrees, respectively.

The measurement of the angle of diagonal cracks was focused on the B-region since it was observed that the crushing areas, which corresponded to the failure regions, were mostly found in that region. In the previous research ${ }^{2}$, a clear tendency of $\beta_{\text {avg }}$ and each possible factor to influence the crack angle could not be found. $\beta_{\text {avg }}$ varied from 27 to 47 degrees and the average values $\beta_{\text {avg }}$ for all specimens was 36.6 degrees. From Table 2, $\beta_{\text {avg }}$ of s300-II, s370-II(13), s370-II(16), and s230-I were 36.0, 33.7, 33.3, and 36.8 degrees, respectively. These values corresponded to those observed in the previous experiment ${ }^{2}$.

\section{MODIFIED PREDICTIVE EQUATION}

\section{(1) Modification of the equation by the authors}

The predictive equation was proposed based on the equilibrium condition of web concrete at the critical section and on the assumption that the critical average diagonal compressive stress on the web $\left(\sigma_{2 \max }\right)$ causes the failure of the member by web crushing without the stirrups yielding ${ }^{2}$. The angle of compressive strut $(\theta)$ of $36.6^{\circ}$ was selected from the average value for all specimens of $\beta_{\text {avg }}$ since an obvious tendency of $\beta_{\text {avg }}$ could not be observed.

Based on the experimental findings in this study combined with the data reported in the previous re-

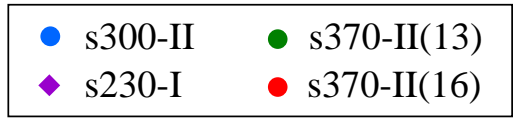

Angle of principal strain [degrees]

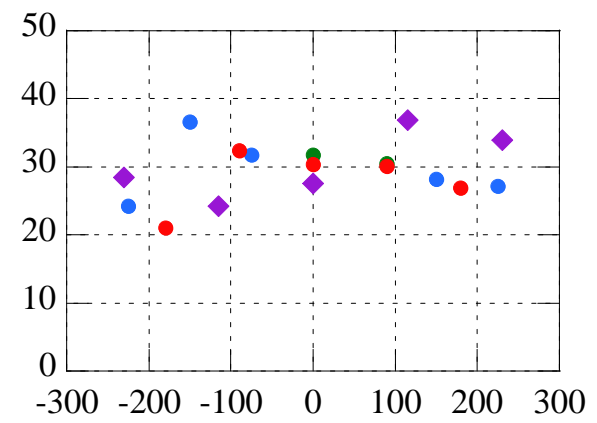

Distance from the middle of shear span [mm]

Fig. 9 Distribution of angle of principal strain.

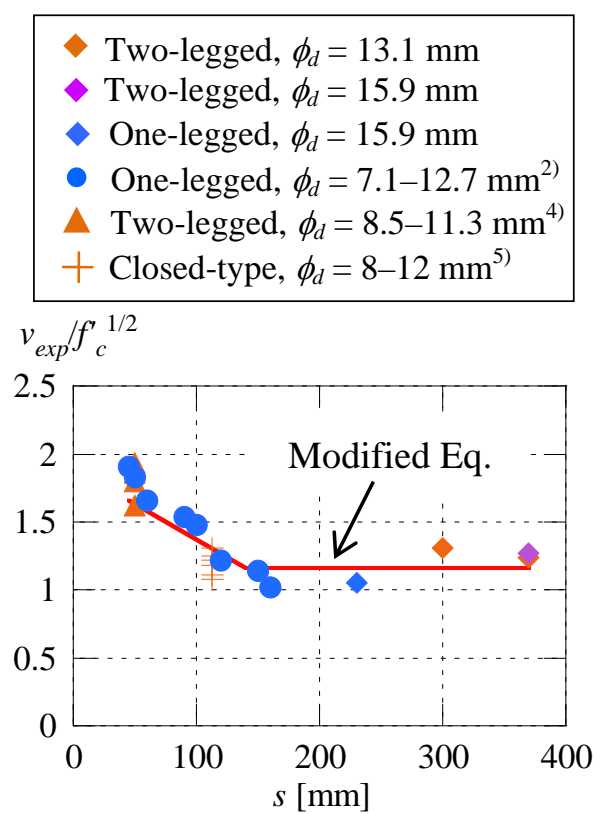

Fig. 10 Modified predictive equation (Eq. (4)).

search by the authors ${ }^{2}$, the following conclusions regarding the effect of influential parameters on the diagonal compressive capacity can be obtained. The diagonal compressive capacity linearly decreased with wider $s$ regardless of its diameters and configuration when $s$ was narrower than $140 \mathrm{~mm}$. The effect of $s$ became negligible when $s$ was approximately wider than $140 \mathrm{~mm}$. The greater effect of $s$ was observed in higher-strength concrete; hence, the effects of $f_{c}^{\prime}$ and $s$ were interrelated ${ }^{2}$. The effect of $a / d$ from 3.0 to $4.5, b_{f} b_{w}$ from 3.75 to 12.5 , and $d$ from $220 \mathrm{~mm}$ to $319 \mathrm{~mm}$ had almost no influence on the diagonal compressive capacity of RC beams ${ }^{2}$. Since the effect of $d$ is negligible, the modified equation will be the function of $s$, rather than $s / d$.

As for the stirrup configuration, even though one-legged stirrups with wide spacing resulted in lower diagonal compressive capacity and the closed-type stirrups are more preferable for the rein- 
forcement detailing in most design standards, the proposed equation, however, becomes rather on the safer side and there is no problem in the practical use of one-legged stirrups. Therefore, the effect of stirrup configuration in wide spacing was averaged in the modification.

To extend the applicable range of the predictive equation by the authors, Eq. (1) was modified to reflect the relationship observed in the experiments by curve fitting as follows:

$$
V_{\text {mod }}=k_{s} \sqrt{f^{\prime}{ }_{c}} b_{w} d \quad\left(s: \mathrm{mm}, f_{c}^{\prime}: \mathrm{N} / \mathrm{mm}^{2}\right)
$$

where $\quad k_{s}=1.9-(s / 190) \geq 1.16$

On the basis of the previous findings ${ }^{2)}$ showing that the effect of $d$ is negligible, the shape of Eq. (4) is illustrated in Fig. 10. The range of application of Eq. (4) are $45 \mathrm{~mm} \leq \mathrm{s} \leq 370 \mathrm{~mm}, 0.6 \% \leq r_{w} \leq 4 \%, 19$ $\mathrm{N} / \mathrm{mm}^{2} \leq f_{c}^{\prime} \leq 165 \mathrm{~N} / \mathrm{mm}^{2}, 3.75 \leq b_{f} / b_{w} \leq 12.5$, and $2.5 \leq a / d \leq 4.5$. The modified predictive equation maintains sufficient simplicity shown in Eq. (1) and accommodates wide stirrup spacing $(160 \mathrm{~mm} \leq s \leq$ $370 \mathrm{~mm}$ ). The accuracy of Eq. (4) will be evaluated in the following sections.

\section{(2) Accuracy of the existing equations}

The experimental results of the total of 39 beams, including those by the authors ${ }^{2)}$, Rangan ${ }^{4)}$ and Leonhardt and Walther ${ }^{5)}$ were gathered. To clarify the applicability of JSCE standards and Placas's equation to HSC, the equations were applied beyond their limitation of compressive strength. All specimens had $f_{c}^{\prime}$ from 19 to $165 \mathrm{~N} / \mathrm{mm}^{2}$ and were reported to have failed in the diagonal compression failure. The comparison of shear capacity from the experiments and the results calculated using Eq. (2) and Eq. (3) are presented in Fig. 11. The average of these ratios (avg.) and the coefficient of variation (C.V.) are also provided in the figure.

Figure 11(a) compares the diagonal compressive capacity from test results with those obtained by the equation by Placas and Regan ${ }^{3)}$ (Eq. (2)). The average of $V_{\text {exp }} V_{\text {Placas }}$ is equal to 0.94 with a C.V. of $14.9 \%$. It implies that Placas's equation can evaluate an average value of the diagonal compressive capacity even if $f^{\prime}{ }_{c}$ approximates $100 \mathrm{~N} / \mathrm{mm}^{2}$. On the contrary, this equation exhibits variations as large as C.V. $=14.9 \%$. In addition, for the authors' data, Eq. (2) overestimates the diagonal compressive capacity in most of the cases, but it underestimates in the other's data. Despite the application of Placas's equation within its applicable $f_{c}^{\prime}$, the equation does not provide comparatively higher accuracy as the average is 0.98 with a C.V. of $16.9 \%(\mathrm{n}=16)$.

JSCE standard specifications (Eq. (3)) demonstrate the average of $V_{\text {exp }} / V_{\text {JSCE }}=1.12$. Figure 11(b) indicates that the JSCE equation underestimates the capacity in almost all specimens. This is obvious since it is a design equation that is normally conservative for safety reasons. Like Placas's equation, the results calculated by Eq. (3) shows variations as large as C.V. $=18.5 \%$. Evaluating the accuracy of the JSCE equation within its $f_{c}^{\prime}$ limitation, the average of $V_{\text {exp }} / V_{J S C E}$ $=1.09$ with a $C . V$. of $21.0 \%(\mathrm{n}=16)$ is obtained. It also gives insubstantial difference in accuracy.

From the reasons mentioned above, the existing equations should be improved in both accuracy and appropriateness since Eq. (2) considers $r_{w}$ as a representative of the effect of the stirrup, which contradicts the reported insignificant effect of stirrup diameter in this study, and Eq. (3) does not consider the effect of the stirrup.

\section{(3) Accuracy of the modified equation}

In Fig. 11(c), the accuracy of the modified equation

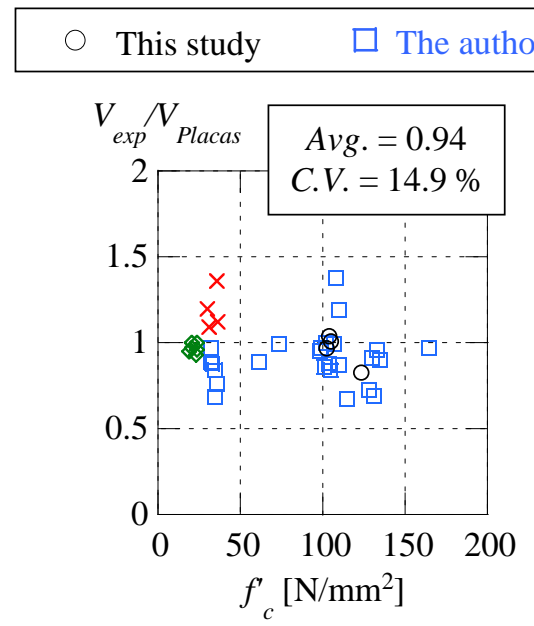

(a) Placas (Eq. (2))

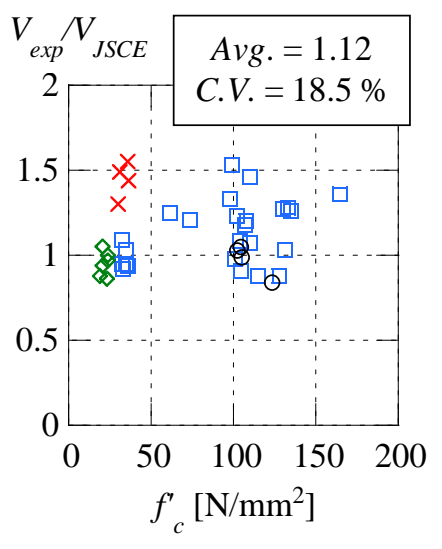

(b) JSCE (Eq. (3))

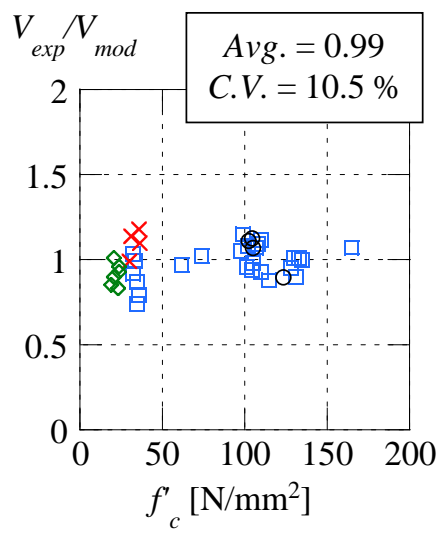

(c) Modified equation (Eq. (4))

Fig. 11 Accuracy of the existing equations. 
was evaluated with the same database used in Section 5.(2). The average of $V_{\text {exp }} / V_{\text {mod }}$ is 0.99 with a coefficient of variation of $10.5 \%$. The modified equation maintains a good correlation with this set of data and can accurately predict diagonal compressive capacity compared to the other existing equations.

It should be noted that, as the modified equation is of empirical type, it can be applied only in the range of the study. This equation can be implemented to beams with compressive strength from 19 to 165 $\mathrm{N} / \mathrm{mm}^{2}$, stirrup ratio ranging from 0.6 to $4 \%$, stirrup spacing within the $45-370 \mathrm{~mm}$ range, flange width-to-web width ratio from 3.75 to 12.5 , shear span-to-effective depth ratio from 2.5 to 4.5, effective depth from 220 to $563 \mathrm{~mm}$, and web width from 40 to $150 \mathrm{~mm}$. In addition, there must be no yielding of stirrups. As for stirrup arrangement, the modified predictive equation covers one-legged (as used in this study and by the authors ${ }^{2)}$ ), two-legged (as used in this study, by the authors ${ }^{2)}$ and Rangan ${ }^{4)}$ ) and closed-type stirrups (as used by Leonhardt and Walther $\left.{ }^{5}\right)$. However, the practical application of one-legged stirrups is not ideal.

There is a possibility that the size effect in the diagonal compression failure may occur when the effective depth of beams is larger than the upper limit in this study, since Walraven and Lehwalter reported a significant size effect on the shear compression failure of short beams ${ }^{9}$. The modified equation might be extended to members with several webs; i.e., box section, since in the JSCE standards, shear capacity of the members shall be considered as similar to beams having $b_{w}$ equal to the total widths of web ${ }^{1)}$. Further investigation, however, is required to validate applicability to this case.

In conclusion, the modified equation covers application to more practical cases of stirrup spacing and maintains sufficient simplicity and precise prediction of the diagonal compressive capacity of RC beams.

\section{CONCLUSIONS}

(1) The diagonal compressive capacity linearly decreases with wider stirrup spacing regardless of its diameters and configuration when stirrup spacing is narrower than $140 \mathrm{~mm}$; however, the effect of spacing becomes negligible when stirrup spacing is wider than $140 \mathrm{~mm}$.

(2) Even though wide stirrup spacing is provided, the diagonal cracks are finely distributed, the crushing area at the web is widely distributed, and the average crack spacing in the horizontal direction of specimens with two-legged stirrups is relatively narrow compared to specimens with one-legged stirrups. It implies that the diagonal stress does not concentrate on a local area of the specimens. It is because sufficient confinement effect provided by the two-legged stirrups can prevent the localization of compressive stress on the struts.

(3) On the basis of the new experimental results, the predictive equation considering the compressive strength of concrete and the stirrup spacing for evaluating the diagonal compressive capacity of RC beams has been modified. The modified equation covers the application to RC beams with practical stirrup spacing $(45 \mathrm{~mm} \leq s \leq 370$ $\mathrm{mm}$ ) while maintaining adequate simplicity and precise accuracy $(A v g .=0.99)$ with low variation (C.V. $=10.5 \%)$ on the prediction of the diagonal compressive capacity of RC beams. The proposed equation can be implemented on beams with compressive strength: $19-165 \mathrm{~N} / \mathrm{mm}^{2}$, stirrup ratio: $0.6-4 \%$, stirrup spacing: $45-370 \mathrm{~mm}$, flange width-to-web width ratio: 3.75-12.5, shear span-to-effective depth ratio: 2.5-4.5, effective depth: 220-563 mm, web width: 40-150 $\mathrm{mm}$ and one-legged, two-legged, and closed-type stirrups.

\section{REFERENCES}

1) Japan Society of Civil Engineers (JSCE) : Standard Specifications for Concrete Structures-2007, Design, 2007.

2) Tantipidok, P., Kobayashi, C., Matsumoto, K., Watanabe, K. and Niwa, J. : Proposed Predictive Equation for Diagonal Compressive Capacity of Reinforced Concrete Beams, Journal of Japan Society of Civil Engineers, Ser. E2 (Materials and Concrete Structures), Vol. 67, No. 4, pp. 535-548, 2011.

3) Placas, A. and Regan, P. E. : Shear Failure of Reinforced Concrete Beams, ACI Journal, Vol. 68, No. 10, pp. 763-774, 1971.

4) Rangan, B. V. : Web Crushing Strength of Reinforced and Prestressed Concrete Beams, ACI Structural Journal, Vol. 88, pp. 12-16, 1991.

5) Leonhardt, F. and Walther, R. : Shear Tests on T-Beam with Varying Shear Reinforcement, Deutscher Ausschuss für Stahlbeton, No. 156, pp. 84, 1963. (in German)

6) Schäfer, K., Schelling, G. and Kuchler, T. : Compression and Transverse Tension in Reinforced Concrete Elements, Deutscher Ausschuss für Stahlbeton, No. 408, Beuth Verlag, GmbH, Berlin, pp. 1-85, 1990.

7) Reineck, K. H. : Theoretical Considerations and Experimental Evidence on Web Compression Failures of High-Strength Concrete Beams, CEB Bulletin D'Information, No. 193, pp. 59-74, 1989.

8) Zakaria, M., Ueda, T., Wu, Z. and Meng, L. : Experimental Investigation on Shear Cracking Behavior in Reinforced Concrete Beams with Shear Reinforcement, Journal of Advanced Concrete Technology, Vol. 7, No. 1, pp. 79-96, Feb. 2009.

9) Walraven, J. and Lehwalter, N. : Size Effect in Short Beams Loaded in Shear, ACI Structural Journal, Vol. 91, No. 5, pp. 585-593, 1994. 